\title{
Sciendo
}

Transport and Telecommunication, 2022, volume 23, no. 1, 73-80

Transport and Telecommunication Institute, Lomonosova 1, Riga, LV-1019, Latvia

DOI 10.2478/ttj-2022-0007

\section{EFFICIENCY OF SHIP OPERATION IN TRANSPORTATION OF OVERSIZED AND HEAVY CARGO BY OPTIMIZING THE SPEED MODE CONSIDERING THE IMPACT OF WEATHER CONDITIONS}

\author{
Svitlana Onyshchenko ${ }^{1}$, Oleksiy Melnyk ${ }^{2}$ \\ ${ }^{1,2}$ Odessa National Maritime University \\ Odesa, Ukraine, Mechnikov str., 34 \\ lonyshenko@gmail.com,2m.onmu@gmail.com
}

\begin{abstract}
Prior to commencing the voyage planning procedure, the entire navigation area on the forthcoming passage should be divided into several sections, depending on various factors, such as traffic density, restricted depths, availability of ship reporting systems, hydrometeorological conditions, high risk navigation areas in order to outline measures to ensure the safety of ship's navigation. In addition, these factors have direct impact on the ship's speed during the voyage. On the other hand, slow steaming can reduce fuel consumption on the same section of the route by $10-15 \%$. Reducing the ship's speed can significantly minimize its operating costs. However, when choosing economically feasible ship's speed it should be kept in mind that reducing the speed can lead to a significant decrease in the number of voyages per year and, consequently, to the reduction of annual freight income. Therefore, a practically important and relevant problem is the necessity to find the speed of ship operation, which will provide a balance between economical fuel consumption and profits from ship operation. The classic approach to optimizing the speed mode of ships is based on the cubic dependence of fuel consumption on speed. Therefore, depending on the distance between ports, the duration of the voyage and the conditions for the time of arrival of the ship to the port, in the modern publications were proposed approaches to the optimization of the speed mode, based on the additional income or time-charter equivalent.
\end{abstract}

Keywords: Ship speed optimization, Oversized and heavy cargo, Route specifics, Weather conditions, Time-charter equivalent

\section{Introduction}

Since this study considers the use of ships for the transportation of non-standard cargo on deck, the main task in the operation of these ships in the specified conditions is to ensure operational efficiency while maintaining the safety of navigation.

The specifics of the oversized and heavy cargo $(\mathrm{OHC})$ transportation process are in the particularities of the formation of cargoflows characterized by the movement of cargo units over significant distances. One of the leading suppliers of this category of cargo from the region of South-East Asia is China. At the same time, a significant number of customers and recipients of goods are located in European countries, including countries of Black sea region, with the corresponding ports of destination.

Ensuring the efficiency of ship operation, as is known, can be achieved through various mechanisms. With regard to the specifics of the process of transportation of the mentioned cargoes, their directions and length of the route, one of the key factors for ensuring the efficiency of ship operation is the implementation of the most efficient speed mode.

\subsection{Literature overview}

The efficiency of ship operation at reduced speed (slow steaming) is due to the fact that the dependence of fuel consumption by the ship on the speed is nonlinear. Some authors suggest that the fuel consumption determined by methods presented by Johnson and Styhre (2015) or this dependence is determined only empirically. However, the exact view of the dependence of fuel consumption on the ship's speed may vary subject on the ship's design, engine type and the current state of the ship's hull.

Ship speed optimization problem with the objective of minimizing the total fuel consumption is studied in Kim et al. (2014) and Psaraftis and Kontovas (2014). Article Adland et al. (2020) deals with optimizing the speed mode of ships is based on the cubic dependence of fuel consumption on speed. Time Charter Equivalent (TCE) Earnings considered in Special report on TCE (2021). The conditions related to the transport of oversize loads considered (Macioszek, 2019), characterised basic types of oversized cargo with the indication of the required documents related to the transport of this type of cargo. Determination of the vessels optimal speed working on carriages of cargoes, freight transactions (Onyshchenko and 
Koskina, 2015). Ship speed optimization (Krata et al., 2019), considering ocean currents and speed optimization for container ship fleet deployment considering fuel consumption studied in (Yang et al., 2020; Gao and $\mathrm{Hu}, 2021$ ). The investigation on how time in port affects efficient ship operation in terms of operating costs (Moon et al., 2014), CO2 emissions and externalities. Developed a flexible framework for the estimation of the fuel consumption-speed curve for ships, which allows for speed-dependent elasticity with endogenous thresholds in paper Onyshchenko et al. (2021).

Modelling of changes in ship's operational condition during the process of transportation of oversized and heavy cargo, its organizational aspects and role of navigational risk assessment explored (Onyshchenko and Melnyk, 2020; Galor, 2009). Determination of an economical shipping route considering the effects of sea state for lower fuel consumption and researches of dependence of fuel consumption on ship speed and methods of selecting optimal operating speed carried out in works by Roh (2013), Kim et al. (2017), Jeon et al. (2018). A scientific research of optimal operating speed of ships in the tramp shipping industry and methods of designing ships for optimal operating speed (Norstad et al., 2011). The authors reviewed the issues of determining the dependence of fuel consumption on ship speed, the impact of high cost of ship fuel on ship maintenance and the forecast of fuel consumption in the future but leaving research gap to the issues of ensuring efficient ship operation considering the influence of weather conditions during the voyage.

\subsection{Problem formulation}

The geographic specificity of $\mathrm{OHC}$ transportation involves considerable distances. One of the main suppliers of this cargo category (including project cargo; equipment and assembly parts for chemical, oil and gas industries; wind generators, etc.) is China. Destination ports for such cargoes are European, including Ukraine.

Since this study deals with the use of dry cargo ships for transportation of this category of cargo, the main task of the operation of these ships under these conditions is to ensure the efficiency of operation while maintaining the safety of navigation.

Ensuring the efficiency of ship operation, as it is known, can be achieved through various mechanisms. Considering specifics of cargoes under consideration and directions of transportation (range of transportation), one of the key tools to ensure efficiency is the use of optimum speed mode.

As mentioned the classical approach to ships' speed optimization is based on cubic dependence of fuel consumption on speed. Therefore, taking into account the distance of the route and the terms of vessel arrival time, modern publications proposed approaches to the optimization of the speed mode based on the daily profit or time-charter equivalent.

\subsection{Materials and methods}

We propose the approach, which provides local consideration of speed mode on the sections of ship passage, considering the limitations of each section under different weather conditions. Under a section of a route, we will understand passage of a vessel from one reference point to another in identical (conditionally identical) operational conditions. Reference points in various regions and for various directions of transportation are established by practice of marine navigation.

An example of dividing the ship's route during transportation of $\mathrm{OHC}$ into sections is shown in Figure 1. Naturally, for such ship passages it is incorrect to determine the optimum speed throughout the entire passage, as proposed in the existing theoretical framework.

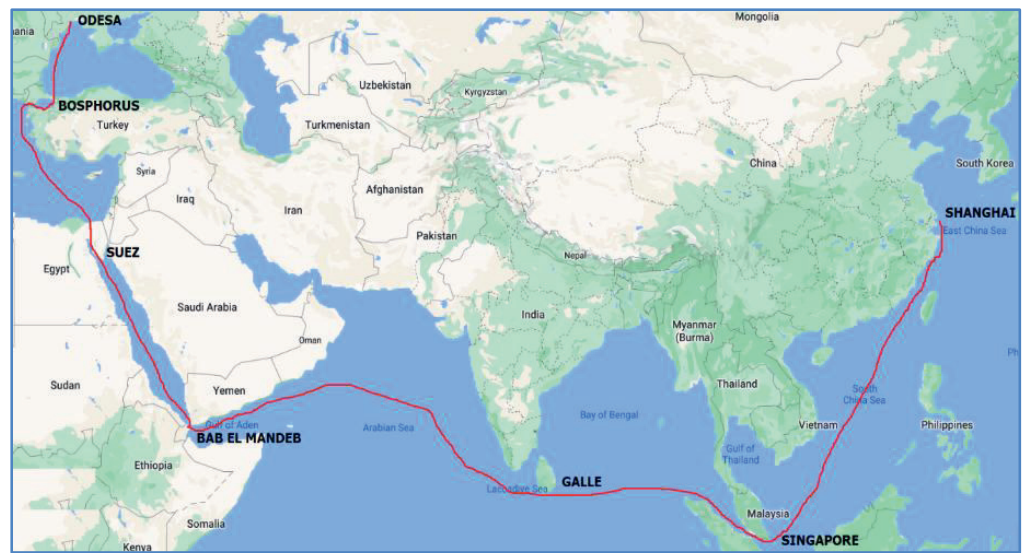

Figure 1. Example of dividing the route into the sections 
Distribution into sections with their inherent features affecting the ship's speed is presented in Table 1.

Table 1. Specifics of route sections

\begin{tabular}{|c|c|}
\hline Section & Characteristics \\
\hline Shanghai - Singapore & $\begin{array}{l}\text { 1. Intensiveness of ship's traffic (divergence maneuvers to avoid collision). } \\
\text { 2. Availability, congestion and high density of fishing vessels which also affects } \\
\text { safety of navigation process. } \\
\text { 3. Currents, the direction and speed of which varies seasonally, directly affecting } \\
\text { both speed increase and decrease. }\end{array}$ \\
\hline Singapore - Galle & $\begin{array}{l}\text { 1. Intensiveness of ship's traffic (divergence maneuvers to avoid collision). } \\
\text { 2. A high-risk navigation area (piracy zone) that requires measures for ship } \\
\text { handling in order to prevent an attack. } \\
\text { 3. Maneuvering in traffic separation system and under the supervision of the ship } \\
\text { traffic control service. } \\
\text { 4. Currents, the direction and speed of which varies seasonally, directly affecting } \\
\text { both speed increase and decrease. }\end{array}$ \\
\hline Galle - Bab El Mandeb & $\begin{array}{l}\text { 1. Impact of weather conditions in seasonal winds, squalls, storms. } \\
\text { 2. A high-risk navigation area (piracy zone) that requires measures for ship } \\
\text { handling in order to prevent an attack. }\end{array}$ \\
\hline Bab El Mandeb - Suez & $\begin{array}{l}\text { 1. A high-risk navigation area (piracy zone) that requires measures for ship } \\
\text { handling in order to prevent an attack. }\end{array}$ \\
\hline Suez-Bosphorus & $\begin{array}{l}\text { 1. Waiting time for the ships' convoy formation. } \\
\text { 2. Canal passage in the reduced speed mode. }\end{array}$ \\
\hline Bosphorus - Odesa & $\begin{array}{l}\text { 1. Strait passage in the reduced speed mode. } \\
\text { 2. Currents, the direction and speed of which varies seasonally, directly affecting } \\
\text { both speed increase and decrease. } \\
\text { 3. Intensiveness of ship's traffic (divergence maneuvers to avoid collision). }\end{array}$ \\
\hline
\end{tabular}

Nevertheless, even local consideration of speed at each section should provide a certain level of efficiency as a whole, which is given in the form of a time-charter-equivalent boundary.

This task arises in two temporal aspects:

1) Before the voyage - in the process of negotiations between shipowner and the charterer on determining of freight amount (operation planning). The shipowner must adequately assess the efficiency of the vessel, with regard to different speed modes on different sections of the passage, considering the possible negative impact of weather conditions and other factors affecting the duration of the passage;

2) During the voyage - in the process of the ship's passage (ship speed correction) - operation of the ship in certain speed regimes, considering the part of the route passed and negative factors already affected.

The basis for solving this problem in the two options under consideration is the next formalization of the efficiency of the ships operation - time-charter equivalent (Special report on TCE, 2021):

$\operatorname{TCE}(V)=\frac{F-R^{\text {port }}-R^{\text {bunk }}(V)}{t^{s t}+\frac{L}{V}} \rightarrow \max$,

where $F$ - freight payment, USD; $R^{\text {port }}$ - port dues and channel charges, USD; $R^{\text {bunk }}(V)$ - bunker fuel costs, USD; $V$ - ship speed, $\mathrm{kn} ; t^{s t}$ - port time, days; $L$ - total route distance, miles.

We note that in the transportation of $\mathrm{OHC}$, the port time has a specific structure, which was previously described.

Then the ship's route can be logically divided into $n$ sections. Let us introduce notations:

$V_{i}, i=\overline{1, n}-$ ship's speed at $i$-th section;

$R^{\text {bunk }}\left(V_{i}\right)$ - bunker fuel costs, USD;

$L_{i}, i=\overline{1, n}$ - distance of the $i$-th section, miles;

$V_{i}^{\max }, i=\overline{1, n}$ - maximum allowable speed at $i$-th section (passing channels and straits), kn;

$V^{\text {min }}$ - minimum allowable speed for the particular ship (no practical sense to operate below it), kn;

$t^{\max }$ - maximum allowed duration of voyage for a shipowner considering commercial conditions of the ship operation, days; 
$t^{\min }$ - minimum allowable limit of voyage time (vessel's arrival, which in some situations does not make commercial sense before certain time), days. In those situations, when there is no such time limit, it is not counted.

$T C E^{\min }$ - minimum acceptable efficiency of ship operation with regard to the situation on the freight market (i.e., level of efficiency that satisfies the shipowner), USD.

Thus, the time-charter equivalent (the main indicator of ship operation efficiency) can be represented as follows:

$$
T C E=\frac{F-R^{\text {port }}-\sum_{i=1}^{n} R^{\text {bunk }}\left(V_{i}\right)}{t^{s t}+\sum_{i=1}^{n} \frac{L_{i}}{V_{i}}}=\frac{F-R^{\text {port }}-c^{b} \times \sum_{i=1}^{n} r^{b}\left(V_{i}\right) \times \frac{L_{i}}{V_{i}}}{t^{s t}+\sum_{i=1}^{n} \frac{L_{i}}{V_{i}}},
$$

where $c^{b}-1$ ton of bunker fuel cost, USD; $r^{b}(V)$ - bunker consumption, $\mathrm{t} ; \frac{L_{i}}{V_{i}}-$ sailing time on each section, days.

Respectively, the running time of the voyage:

$$
t^{v}=\sum_{i=1}^{n} \frac{L_{i}}{V_{i}} \text {. }
$$

In this case, the minimum efficiency margin acceptable to the shipowner must be met:

$$
\operatorname{TCE}(V)=\frac{\text { F-R }{ }^{\text {port }}-\sum_{i=1}^{n} R^{\text {bunk }}\left(V_{i}\right)}{t^{s t}+\sum_{i=1}^{n} \frac{L_{i}}{V_{i}}} \geq T C E^{\text {min }} .
$$

When determining the optimal ship speed, it is necessary to take into account, on the one hand the limitation on the voyage time:

$$
t^{v}+t^{s t}=\sum_{i=1}^{n} \frac{L_{i}}{V_{i}}+t^{s t} \leq t^{\max }
$$

on the other hand - restrictions on the operating speed, considering the peculiarities of the section of the passage:

$$
V^{\min } \leq V_{i} \leq V_{i}^{\max }, i=\overline{1, n} \text {. }
$$
conditions.

As a rule, under favorable weather conditions, but this provision is not met in adverse weather

Indeed, $V_{i}^{\max }, i=\overline{1, n}$ depends largely on weather conditions: in the same region of passage (considered section) under favorable weather, conditions can be significantly higher than under unfavorable ones. Thus, especially during stormy periods, when planning a voyage and its efficiency, it is necessary to consider the influence of weather conditions on ship operation in terms of speed mode.

The weather conditions affecting the operation of the ship is proposed to be divided into three categories (three situations):

A - sea passage goes in good weather conditions (1-5 Beaufort scale);

$\mathrm{B}$ - sea passage is under adverse weather conditions (up to 7-8 Beaufort scale);

$\mathrm{C}$ - sea passage is held under severe weather conditions (9-11 Beaufort scale).

Consider this approach for further study.

Therefore, $V_{i}^{\max }, i=\overline{1, n}$ must be presented as three options for major weather conditions:

$V_{i}^{\max }=\left\{V_{i}^{\max }(A), V_{i}^{\max }(B), V_{i}^{\max }(C)\right\}, i=\overline{1, n}$. 
The following is true:

$V_{i}^{\max }(C)<V_{i}^{\max }(B)<V_{i}^{\max }(A), i=\overline{1, n}$.

Thus, (8) defines the boundaries of safe speed under certain weather conditions $(A, B, C)$ on the $i$-th section of the passage.

In this case (6) is also converted as follows:

$$
\begin{aligned}
V^{\text {min }} & \leq V_{i} \leq V_{i}^{\text {max }}(A), \\
V^{\text {min }} & \leq V_{i} \leq V_{i}^{\max }(B), \\
V^{\text {min }} & \leq V_{i} \leq V_{i}^{\max }(C), i=\overline{l, n} .
\end{aligned}
$$

Consequently, it is true for each section:

$$
V_{i}^{o}=\left\{V^{o}, V_{i}^{\max }\right\}, i=\overline{1, n}
$$

and $V_{i}^{o}=V^{o}$ under favorable conditions, under unfavorable conditions fairly $V_{i}^{o}=V^{o}$ and $V_{i}^{o}=V_{i}^{\max }$ or depending on the degree of "non-favorability" of the weather conditions and the characteristics of the operation of a particular ship.

Thus, there are three options for the efficiency of ship operation in different weather conditions:

$$
\begin{aligned}
& T C E(V, A)=\frac{F-R^{\text {port }}-R^{\text {bunk }}(V)}{t^{s t}+\frac{L}{V}}, V^{\text {min }} \leq V \leq V^{\max }(A), \\
& T C E(V, B)=\frac{F-R^{\text {port }}-R^{\text {bunk }}(V)}{t^{s t}+\frac{L}{V}}, V^{\text {min }} \leq V \leq V^{\max }(B), \\
& T C E(V, C)=\frac{F-R^{\text {port }}-R^{\text {bunk }}(V)}{t^{s t}+\frac{L}{V}}, V^{\text {min }} \leq V \leq V^{\max }(C),
\end{aligned}
$$

which, given the decomposition of the passage into sections, are converted into:

$$
\begin{aligned}
& T C E\left(V_{1}, V_{2}, \ldots, V_{n}, A\right)=\frac{F-R^{\text {port }}-c^{b} \times \sum_{i=1}^{n} r^{b}\left(V_{i}\right) \times \frac{L_{i}}{V_{i}}}{t^{s t}+\sum_{i=1}^{n} \frac{L_{i}}{V_{i}}}, V^{\min } \leq V_{i} \leq V^{\max }(A), \\
& T C E\left(V_{1}, V_{2}, \ldots, V_{n}, B\right)=\frac{F-R^{\text {port }}-c^{b} \times \sum_{i=1}^{n} r^{b}\left(V_{i}\right) \times \frac{L_{i}}{V_{i}}}{t^{s t}+\sum_{i=1}^{n} \frac{L_{i}}{V_{i}}}, V^{\min } \leq V_{i} \leq V^{\max }(B), \\
& T C E\left(V_{1}, V_{2}, \ldots, V_{n}, C\right)=\frac{F-R^{\text {port }}-c^{b} \times \sum_{i=1}^{n} r^{b}\left(V_{i}\right) \times \frac{L_{i}}{V_{i}}}{t^{s t}+\sum_{i=1}^{n} \frac{L_{i}}{V_{i}}}, V^{\min } \leq V_{i} \leq V^{\max }(C),
\end{aligned}
$$

Suppose, according to weather forecasts, the sections with the appropriate type of weather conditions are set: $U_{A}, U_{B}, U_{C}$ respectively. Then it is possible to establish the length of the part of the route with these or those weather conditions: 


$$
L_{A}=\sum_{k \in U_{A}} L_{k}, L_{B}=\sum_{j \in U_{B}} L_{j}, L_{C}=\sum_{w \in U_{C}} L_{w}
$$

Thus, the actual efficiency of ship operation, considering the impact of weather conditions:

$$
T C E=\frac{F-R^{p o r t}-c^{b} \times\left[\frac{L_{A}}{V_{A}} \times r^{b}\left(V_{A}\right)+\frac{L_{B}}{V_{B}} \times r^{b}\left(V_{B}\right)+\frac{L_{C}}{V_{C}} \times r^{b}\left(V_{C}\right)\right]}{t^{s t}+\frac{L_{A}}{V_{A}}+\frac{L_{B}}{V_{B}}+\frac{L_{C}}{V_{C}}},
$$

where $V_{A}, V_{B}, V_{C}$ accepted speed values for different weather conditions.

Obviously, $V_{A}, V_{B}, V_{C}$ corresponds to either the optimum speed calculated for the entire passage $V^{O}$ or the maximum allowable speed for the given weather conditions: $V^{\max }(A), V^{\max }(B), V^{\max }(C)$, as a rule:

$$
\begin{aligned}
& V_{A}=V^{o} ; \\
& V_{B}=\left\{\begin{array}{c}
V^{O}, V^{O}<V^{\max }(B), \\
V^{\max }(B) ;
\end{array}\right. \\
& V_{C}=V^{\max }(C) .
\end{aligned}
$$

\section{Comment (14):}

- under favorable weather conditions $(A)$, the speed limits are generally much higher than the optimal speed level $V^{O}$, so for sections with favorable weather conditions, the speed is taken as $V^{O}$;

- under adverse weather conditions $(B)$ two options are possible depending on the value - either the maximum allowable under the given conditions or the optimum;

- in adverse weather conditions $(C)$, the allowable speed is much lower than the optimum speed, so it is the allowable speed in these weather conditions that is used on sections with type $\mathbf{C}$ weather conditions.

Since the value of the optimum speed was determined on the basis of (1) without consideration of sections where the speed limit is significantly lower due to weather conditions, it is proposed to "clarify" the value of the optimum speed on the basis of the following expression in order to take into account these factors:

$$
T C E(V)=\frac{F-R^{\text {port }}-c^{b} \times\left[\frac{L_{A}}{V o} \times r^{b}(V)+\frac{L_{B}}{V_{B}} \times r^{b}\left(V_{B}\right)+\frac{L_{C}}{V_{C}} \times r^{b}\left(V_{C}\right)\right]}{t^{s t}+\frac{L_{A}}{V o}+\frac{L_{B}}{V_{B}}+\frac{L_{C}}{V_{C}}} \rightarrow \underset{V}{\max },
$$

or

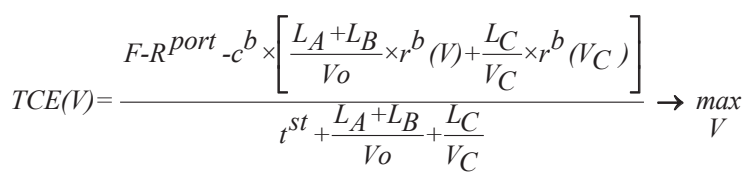

depending on the ratio of $V^{O}$ and $V^{\max }(B)$.

\section{Conclusion}

Consequently, based on the identification of passage sections with adverse weather conditions of different types (B and $\mathrm{C}$ ), correction or recalculation of optimal speed value, which maximizes the ship performance indicator neglecting the weather conditions at different passage sections, is performed. That 
approach allows planning the ship's route and assessing the degree of its efficiency, taking into account the influence of weather conditions on the process of ship operation with regard to the speed mode.

It is necessary to note, that such approach is adequate to real processes of ships operation, and, hence, provides reliability of results - optimum value of speed and level of efficiency indicator - timecharter equivalent.

Also worth pointing out that, the proposed approach is based on the most probable weather scenario during the voyage, meaning that the probabilities of a particular weather situation in a particular region are determined by the season and can be estimated based on statistical data, considering the available information on the weather forecast for the upcoming voyage.

\section{References}

1. Adland, R., Cariou, P., Wolff, F.C. (2020) Optimal ship speed and the cubic law revisited: Empirical evidence from an oil tanker fleet. Transportation Research Part E: Logistics and Transportation Review, 140, 101972. DOI:10.1016/j.tre.2020.101972.

2. Galor, W. (2009) The role of navigational risk assessment during ship's manouvering in limited waters. Journal of KONES Powertrain and Transport, 16(2), 117-124. Retrieved: https://citeseerx.ist.psu.edu/viewdoc/download?doi=10.1.1.915.8718\&rep=rep1\&type=pdf (Aug. 1, 2021).

3. Gao, C.F., Hu, Z.H. (2021) Speed optimization for container ship fleet deployment considering fuel consumption, Sustainability, MDPI, Open Access Journal, 13(9), 1-18. DOI: 10.3390/su13095242

4. Jeon, M., Noh, Y., Shin, Y., Lim, O.K., Lee, I., Cho, D. (2018) Prediction of ship fuel consumption by using an artificial neural network. J. Mech. Sci. Technol., 32, 5785-5796. DOI:10.1007/s12206018-1126-4.

5. Johnson, H., Styhre, L. (2015) Increased energy efficiency in short sea shipping through decreased time in port. Transportation Research Part A: Policy and Practice, 71, 167-178. DOI:10.1016/j.tra.2014.11.008.

6. Kim, J.G., Kim, H.J., Lee, P. (2014) Optimizing ship speed to minimize fuel consumption. Transportation letters, 6, 109-117. DOI:10.1179/1942787514Y.0000000016.

7. Kim, M., Hizir, O., Turan, O., Day, S., Incecik, A. (2017) Estimation of added resistance and ship speed loss in a seaway. Ocean Engineering, 141, 65-76. DOI:10.1016/j.oceaneng.2017.06.051.

8. Krata, P., Vettor, R., Soares, C.G. (2019) Bayesian approach to ship speed prediction based on operational data. In: Proceedings of the 8th International Conference on Collision and Grounding of Ships and Offshore Structures (ICCGS 2019), Lisbon, 21-23 October. DOI:10.1201/9781003002420-47.

9. Macioszek, E. (2019) Conditions of oversize cargo transport. Scientific Journal of Silesian University of Technology. Series Transport, 102, 109-117. DOI:10.20858/sjsutst.2019.102.9.

10. Melnyk, O. (2020) Organization of the transportation process of oversized cargo by means of transport. The role and position of maritime transport in this process. Municipal economy of cities, 1(154), 231-239. DOI:10.33042/2522-1809-2020-1-154-231-239.

11. Moon, D., Woo, J.K. (2014) The impact of port operations on efficient ship operation from both economic and environmental perspectives. Maritime Policy \& Management, 41, 444-461. DOI:10.1080/03088839.2014.931607.

12. Norstad, I., Fagerholt, K., Laporte, G. (2011) Tramp ship routing and scheduling with speed optimization. Transportation Research Part C: Emerging Technologies, 19, 853-865. DOI:10.1016/j.trc.2010.05.001.

13. Onyshchenko, S., Koskina, Yu. (2015) Research of the effect of terms and conditions of an offer on successful conclusion of the freight transaction. Eastern-European Journal of Enterprise Technologies, 6(3), 25-32. DOI:10.15587/1729-4061.2015.55738.

14. Onyshchenko, S., Melnyk, O. (2020) Modelling of changes in ship's operational condition during transportation of oversized and heavy cargo Technology audit and production reserves, 6/2(56), 66-70. DOI: 10.15587/2706-5448.2020.221653.

15. Onyshchenko, S., Shibaev, O., Melnyk, O. (2021) Assessment of potentially negative impact of a system of factors on a ship's operational condition during the transportation of oversized and heavy cargo. Transactions on Maritime Science, 10(1), 126-134. DOI:10.7225/toms.v10.n01.009.

16. Psaraftis, H., Kontovas, C. (2014) Ship speed optimization: Concepts, models and combined speedrouting scenarios. Transportation Research Part C: Emerging Technologies, 44, 52-69. DOI:10.1016/j.trc.2014.03.001. 
17. Roh, M.I. (2013) Determination of an Economical Shipping Route Considering the Effects of Sea State for Lower Fuel Consumption. International Journal of Naval Architecture and Ocean Engineering, 5(2), 246-262. DOI:10.3744/JNAOE.2013.5.2.246.

18. Special report on TCE. (2021). Speed up for what? Hellenic shipping news. Retrieved: https://www.hellenicshippingnews.com/wp-content/uploads/2015/04/Copy-of-Special-Report-TCEENG.pdf (Aug. 1, 2021).

19. Yang, L., Chen, G., Zhao, J., Rytter, N. (2020) Ship speed optimization considering ocean currents to enhance environmental sustainability in maritime shipping, Sustainability, MDPI, Open Access Journal, 12(9), 1-24. DOI:10.3390/su12093649. 